\title{
Aprendendo e Ensinando Através do Uso de Materiais Recicláveis na Educação Infantil
}

\author{
Learning and Teaching Through the Use of Recyclable Materials \\ In Childhood Education
}

\author{
Nadia Cristina Schneider Bisognin ${ }^{1}$ \\ ${ }^{1}$ Pedagoga formada pela UFSM (2013). Trabalha na Escola de Educação Infantil Pequeno Lar - \\ Concursada na função de atendente pela Prefeitura Municipal de Panambi (RS).
}

\section{Resumo}

Este artigo apresenta reflexões sobre as práticas pedagógicas realizadas com uma turma de Educação Infantil na rede municipal no município de Panambi (RS). O objetivo geral consistiu em investigar, descrever e analisar os registros reflexivos acerca das atividades lúdicas desenvolvidas na Educação Infantil, destacando a importância das interações e brincadeiras para a aprendizagem utilizando de materiais pedagógicos elaborados a partir de resíduos. A metodologia utilizada foi a pesquisa bibliográfica, de campo e participante. Para elaboração deste artigo, buscou-se referencial nos teóricos Wajskop (1995), Santos (2000), Pereira (2006; 2009), Freire (2002), Negrine (1994) e Kishimoto (1998; 2010), entre outros pesquisadores na área dos resíduos sólidos.

Palavras-chave: aprendizagem. lúdico. práticas pedagógicas. educação ambiental.

\begin{abstract}
This paper presents considerations about the pedagogical practices carried out with a class of Childhood Education in the public schools system in the city of Panambi (RS). The overall objective consisted in investigating, describing and analyzing the reflexive records about the playful activities developed in the Childhood Education, highlighting the importance of the interactions and entertainment to learning using pedagogic materials made from waste. The methodology used was the bibliographic research, of field and participating. To draw up this article we sought references on the theorists Wajskop (1995), Santos (2000), Pereira (2006; 2009), Freire (2002), Negrine (1994) and Kishimoto $(1998,2010)$, among other researchers in the area of solid waste.
\end{abstract}

Keywords: learning. playful. pedagogical practices. environmental education. 


\section{Introdução}

Este artigo trata sobre relato de práticas pedagógicas na educação infantil, a utilização de resíduos sólidos na elaboração de materiais pedagógicos, os conceitos de resíduos e lixos, a importância do lúdico como recurso pedagógico na educação infantil.

A brincadeira é uma forma de comunicação e através do brincar as crianças reproduzem e recriam o seu dia a dia, num mundo de imaginação e fantasia. Ao participar das brincadeiras, a criança aprende e desenvolve sua autonomia e criatividade e ao mesmo tempo estabelece uma relação entre jogo e a aprendizagem.

Diante da diversidade de brincadeiras, jogos e brinquedos que podem ser disponibilizados para trabalhar com as crianças na Educação Infantil, este artigo apresenta um referencial teórico baseado em diversos autores, os quais descrevem a importância de trabalhar atividades lúdicas na aprendizagem das crianças na Educação Infantil.

Wajskop (1995), Santos (2000), Pereira (2006; 2009), Freire (2002), Negrine (1994), Kishimoto (1998; 2010), entre outros autores abordam a importância das brincadeiras como recurso pedagógico para a aprendizagem e o desenvolvimento significativo das crianças. De acordo com o que foi mencionado, esse artigo relata investigação de registros reflexivos acerca das atividades lúdicas desenvolvidas na Educação Infantil envolvendo materiais recicláveis no Desenvolvimento de atividades.

\section{Metodologia}

Para a realização deste artigo, utilizou-se da pesquisa bibliográfica, de campo e participante. Primeiramente fez-se um levantamento com busca em livros e materiais diversos em sites confiáveis da internet sobre a temática. A pesquisa de campo refere-se às reflexões sobre as práticas realizadas no estágio realizado na Educação Infantil. Esta foi baseada na perspectiva participante defendida por Brandão (2006). Segundo este autor, deve-se conhecer a realidade, participar da produção do conhecimento e tomar posse desses, adquirido na realidade, com a finalidade de aprender a reescrever a história através de sua história, para transformá-la.

Para Perrenoud (2002, p. 36), é necessário que o professor "[...] reexamine constantemente seus objetivos, seus procedimentos, suas evidências e seus saberes". Entende-se que este autor destaca a importância de escrever sobre a prática pedagógica, sobre a docência, sobre o planejamento e o processo de acompanhamento da aprendizagem, tendo em vista a necessidade de permanentemente buscar atingir aos objetivos propostos com vistas a desafiar e superar as dificuldades dos alunos.

As atividades práticas foram desenvolvidas numa Escola da rede Municipal de Panambi/RS. A escola possui aproximadamente 523 alunos distribuídos da Educação Infantil ao Ensino Fundamental. Na turma 23\% eram meninas e 77\% meninos, denominada jardim A, no turno da manhã. Do total de crianças, 90\% possuíam 5 anos completos e 10\% completaram 5 anos até final de 2012.

As práticas de estágio foram realizadas no período de 07 de maio a 12 de junho de 2012, totalizando cem horas aula, com a colaboração ativa da professora regente. Do total de crianças da turma da Educação Infantil 7,7\% residem na zona rural e utilizam o transporte municipal gratuito. Os 93,3\% residem na zona urbana, alguns os pais trazem e outros vêm com os irmãos que estudam em outras turmas. Os pais são participativos, dialogam com as professoras, perguntando como seu(sua) o filho(a) está aprendendo na sala de aula, e comentando os relatos entusiasmados das crianças sobre as atividades realizadas.

A atividade que será relatada neste artigo, foi utilizado em práticas de educação ambiental reaproveitando materiais diversos que são utilizados no cotidiano das famílias, cujas crianças frequentam os diferentes anos no ensino fundamental.

\section{Referencial Teórico}

A palavra lúdico quer dizer brincar, no brincar incluem-se os jogos, os brinquedos e as brincadeiras. Segundo Santos (2000), as atividades lúdicas devem gerar situações estimuladoras e eficazes para que ocorram as aprendizagens significativas. 
As crianças desenvolvem diversas habilidades que vão sendo aperfeiçoadas ao longo de sua infância. Portanto, o professor ao planejar deve oportunizar situações de aprendizagens diferenciadas, a fim de que os estímulos das crianças possam ser exercitados. As aprendizagens, para Junior (2009), podem ser oportunizadas, através de brinquedos, jogos e brincadeiras.

Com relação ao jogo, esse deve ser de fácil compreensão e possuir regras simples, caráter desafiador, ser interessante para a criança. Ao selecionar o tipo de jogo, o professor deve levar em consideração o espaço disponível e material didático. Ao educador, cabe estimular as crianças durante a realização do jogo, pois estas precisam conhecer as regras e os limites (KISHIMOTO, 1998).

A brincadeira é considerada oportunidade para as crianças se comunicarem e relacionarem-se umas com as outras, pois brincando aprendem sobre o mundo que acerca e passa a ter acesso a melhor forma de inserir-se nesse mundo. Nesta compreensão, os jogos, os brinquedos e as brincadeiras são atividades essenciais e fundamentais da infância (KISHIMOTO, 1998).

O brinquedo favorece "a imaginação, a confiança e a curiosidade, proporciona a socialização, o desenvolvimento da linguagem, do pensamento, da criatividade e da concentração" (BATISTA; MORENO; PASCHOAL, 2000, p. 110). Para Santos (2000), o jogo estimula o interesse do educando, desenvolve níveis diferentes de experiência pessoal e social e também promove novas descobertas, construindo e ampliando os seus conhecimentos.

A Educação Infantil se baseia nas necessidades e interesses das crianças, oportunizando que as mesmas desenvolvam habilidades que permitam atitudes de expressão, de autonomia, aceitar críticas e aprender ser responsável (PEREIRA, 2009).

O educador deve conhecer a criança investigando como é sua vivência na família e na sociedade, e a partir disso, oportunizar os jogos a fim de que esse possa manifestar as suas vivências, sendo o adulto uma referência importante. Para Negrine (1994, p.20) [...] "as atividades lúdicas estão recheadas de ações investigativas, de exercício e de jogo. Portanto, quando a criança chega a escola, traz consigo toda uma pré-história, construída a partir de suas vivências, grande parte delas através da atividade lúdica".

A Lei de Diretrizes e Bases da Educação Brasileira (BRASIL, 1996) trouxe significados e avanços com relação ao tratamento de situações que se refere à criança.Segundo o Art. $29^{\circ}$ da Seção II, a educação infantil corresponde a "primeira etapa da educação básica, tem como finalidade o desenvolvimento integral da criança até seis anos de idade, em seus aspectos físico, psicológico, intelectual e social, complementando a ação da família e da comunidade" .O Art. $30^{\circ}$ coloca que a educação infantil será oferecida em: "I - creches, ou entidades equivalentes, para crianças de até três anos de idade; II pré-escolas, para as crianças de quatro a seis anos de idade". A educação infantil deve ser avaliada mediante o acompanhamento e o registro do seu desenvolvimento, sem o objetivo de promoção. A Educação Infantil possui objetos próprios, ligados à idade, às condições culturais e ao nível de desenvolvimento alcançado pelas crianças.

Wajskop (2005, p. 30) ressalta que: "Os conteúdos veiculados durante as brincadeiras infantis bem como os temas das brincadeiras, os materiais para brincar, as oportunidades para interações sociais e o tempo disponível são todos fatores que dependem basicamente do currículo proposto pela escola".

Os Artigos $9^{\circ}$ ao $12^{\circ}$ das Diretrizes Curriculares de Educação Infantil abordam a análise do brincar na Educação Infantil. O Artigo $9^{\circ}$ chama a atenção para as práticas norteadoras e sugerem que ao proporcionar brincadeiras às crianças, o professor deve pensar nas interações: com a professora, com as crianças e com os brinquedos e materiais.

Em relação às práticas pedagógicas as Diretrizes Curriculares Nacionais de Educação Infantil (BRASIL, 2010, p.25-27) colocam que estas devem garantir experiências diversas que:

\footnotetext{
Promovam o conhecimento de si e do mundo por meio da ampliação de experiências sensoriais, expressivas, corporais que possibilitem movimentação ampla, expressão da individualidade e respeito pelos ritmos e desejos da criança;

Favoreçam a imersão das crianças nas diferentes linguagens e o progressivo domínio por elas de vários gêneros e formas de expressão: gestual, verbal, plástica, dramática e musical;

Possibilitem às crianças experiências de narrativas, de apreciação e interação com a linguagem oral e escrita, e convívio com diferentes suportes e gêneros textuais orais e escritos;

Recriem, em contextos significativos para as crianças, relações quantitativas, medidas, formas e orientações espaço temporais;

Ampliem a confiança e a participação das crianças nas atividades individuais e coletivas;
} 
Possibilitem situações de aprendizagem mediadas para a elaboração da autonomia das crianças nas ações de cuidado pessoal, auto-organização, saúde e bem-estar;

Possibilitem vivências éticas e estéticas com outras crianças e grupos culturais, que alarguem seus padrões de referência e de identidades no diálogo e conhecimento da diversidade;

Incentivem a curiosidade, a exploração,o encantamento, o questionamento, a

indagação e o conhecimento das crianças em relação ao mundo físico e social, ao tempo e à natureza;

Promovam o relacionamento e a interação das crianças com diversificadas manifestações de música, artes plásticas e gráficas, cinema, fotografia, dança, teatro, poesia e literatura;

Promovam a interação, o cuidado, a preservação e o conhecimento da biodiversidade e da sustentabilidade da vida na Terra, assim como o não desperdício dos recursos naturais.

Ao planejar, o professor pode levar em consideração o que foi mencionado no parágrafo anterior e ter em mente que o trabalho com as crianças pequenas é uma tarefa que exige muita responsabilidade, afetividade, compromisso, amor, atitude e atenção. O professor numa abordagem lúdica, proporciona a produção do conhecimento, pois Freire (2002, p.52), coloca que "ensinar não é transferir conhecimentos, mas criar possibilidades para a sua própria produção". São diversas as formas de promover a expressão e aprendizagem infantil, por meio das brincadeiras e interações.

Levando em consideração o exposto pelos teóricos, aproveitei diversos tipos de resíduos para elaborar um boneco para cada criança e servir de material pedagógico, o qual foi explorado no decorrer das aulas.

O conceito de resíduo e lixo pode variar conforme a época e o lugar. Depende de fatores jurídicos, econômicos, ambientais, sociais e tecnológicos como afirma Calderoni (1998). A diferença na conceituação do termo resíduo e lixo conforme a situação em que seja aplicada. Conforme Hempe (2013) lixo é "todo e qualquer material descartado pela atividade humana, doméstica, social e industrial, que é jogado fora, pois para o seu proprietário não tem mais valor". Já para Amorim (2010) "lixo é tudo o que é descartado e que não é percebido e que não possui utilidade imediata". A pesquisadora Hempe (2013) define resíduo como sobra no processo produtivo e é equivalente a refugo ou rejeito. Em outras situações, a conceituação de resíduo é equivalente a lixo. O vocábulo lixo pode ser chamado de resíduo, quando é descartado e é reutilizado. Os pesquisadores mencionados definem ainda que a denominação lixo geralmente é utilizada no cotidiano das escolas. A pesquisadora em sua dissertação de mestrado Hempe (2013, p.22), define resíduo sólido ou lixo como sendo "todo o material sólido ou semi-sólido indesejável e que necessita ser removido por ter sido considerável inútil por quem o descarta, em qualquer recipiente destinado a este fim".

Os conceitos de resíduos e lixos são sinônimos como pode ser percebido pelas várias denominações. Há de se destacar, pois para quem descarta alguma coisa pode não ter serventia, para outras pessoas pode vir a tornar-se matéria prima para um novo produto ou processo. Para Hempe (2013) a ideia de reaproveitamento do lixo é um convite à reflexão do próprio conceito de resíduos sólidos. Neste sentido é que foi proposto as crianças que juntassem os diversos resíduos, para posteriormente serem reaproveitados na elaboração de um boneco.

É possível identificar três formas de destinação final dos resíduos sólidos no Brasil: lixão, aterro controlado e aterro sanitário. Freire (2009, p.22) apud Hempe (2012) apresenta a descrição das formas de destinação dos resíduos no Brasil:

O lixão forma inadequada de disposição final dos resíduos sólidos, que se caracteriza pela simples descarga de resíduos em determinadas áreas, sem medidas de proteção ao meio ambiente e proteção à saúde pública; $\mathrm{O}$ aterro controlado é uma forma de disposição criada com vistas à diminuição dos efeitos adversos do lançamento do lixo a céu aberto;

O aterro sanitário é a utilização de técnica de disposição de Resíduos sólidos urbanos que utilizam o solo, tendo a preocupação de não causar danos à saúde pública e à segurança da população, procurando minimizar os impactos ambientais.

O município de Panambi (RS) já teve as três formas de destinação dos resíduos sólidos. Atualmente conta com um aterro controlado (HEMPE, 2013).

\section{Resultados e Discussões}

Este artigo é resultado da reflexão de práticas pedagógicas realizadas com crianças da Educação Infantil. Foi elaborado para ser apresentado no III Congresso Internacional de Educação Ambiental/ 
Curso de Especialização em Educação Ambiental - UFSM e IX Seminário Municipal do Meio Ambiente que foi realizado em setembro de 2014, em Panambi - RS.

As práticas pedagógicas aconteceram no estágio de Educação Infantil. Nesta foram oportunizadas aplicação de várias atividades lúdicas. E para este relato foi selecionado uma prática, a qual foi reaproveitados diversos resíduos.

A escola organizava-se por meio de tema gerador e a partir do surgiram perguntas. Destas foi selecionada uma. As perguntas movem o mundo, durante as cinco semanas do estágio foram planejadas e organizadas as atividades tendo como fio condutor os sub-temas diversificados de acordo com as dúvidas e interesses dos próprios alunos ${ }^{1}$

Nesse sentido, aceitamos o convite e desafio de Ostetto (2010), quando afirma a importância de "registrar a experiência vivida, descrevendo e analisando a complexa trama do cotidiano educativo, com seus feios, laços e nós, tem sido apontada e assumida como essencial para a qualificação da prática pedagógica" (p.13).

A atividade que relato foi à construção de um boneco, decisão tomada em conjunto ${ }^{2}$, após conversa com as crianças sobre o corpo humano. Para a confecção do boneco foi utilizado tampas de garrafa pet coloridas, copinhos de iogurte e elástico de diversas cores, bolinha de desodorante rolon. Os materiais foram solicitados aos alunos. Segue observações registradas no meu diário reflexivo sobre as práticas de educação ambiental realizadas no estágio supervisionado nos anos iniciais.

\begin{abstract}
Hoje foi muito legal e inesquecível, foi feito o boneco de material reciclável, e tive muito serviço. A maioria dos alunos trouxe o material solicitado, o que faltou eu distribui, pois havia levado. Os alunos durante uma semana trouxeram materiais, assim eu furei as tampas e os potes de iogurte.

A semana inteira os alunos e as mães comentavam a expectativa com esse boneco. Os alunos participaram na montagem, contaram os números e escolheram as cores, somente ajudei na hora do laço. No final, cada aluno apresentou o seu boneco, disse as cores que tinha e o nome que deram ao boneco. Na hora de terminar a aula, em quanto que os alunos brincavam com seus bonecos, a professora regente tirou foto para colocar no blog da escola, fiquei surpresa e emocionada, pois uns professores e a coordenadora me apoiavam e diziam que era muita coragem. $\mathrm{O}$ olhar da criança faceira pela atividade realizada nossa muito gratificante, mas tive ajuda de uma voluntária, pois eu sendo a professora a professora regente só observava. Fiquei muito feliz por esse desafio e a realização então que foi com sucesso (Diário Reflexivo, 18/05/2012).
\end{abstract}

Esta atividade teve o objetivo de trabalhar as partes do corpo humano, contagem e às cores. As crianças confeccionaram seu boneco com o auxílio da estagiária e uma ajudante de um projeto da escola (alunos voluntários). Depois de escolher o nome do seu boneco, cada criança apresentou aos colegas, destacando as cores que tinha no boneco, quantidade de tampinhas que continha em cada braço e perna, um ajudando ao outro. Segue imagem do boneco, figura 1.

\footnotetext{
1 Sub-temas: Como é o corpo por dentro? Este sub-tema foi escolhido, porque é uma pergunta dos alunos em sala de aula para a busca de conhecimento e entendimento de como funciona o corpo humano por dentro. Como o alimento chega na barriga? A escolha deste sub-tema foi para tirar as dúvidas dos alunos de como funciona a parte interna do nosso corpo, e em especial nossa digestão. Como é um kiwi? A escolha do tema para que o aluno esclareça suas dúvidas da fruta kiwi, também foi por causa da letra estrangeira que é o $\mathrm{k}$, incluída no alfabeto. Da onde vem o nome? A escolha deste tema é a curiosidade que o aluno tem da origem de seu nome, descoberta do motivo de seu nome e seu significado. O que é família? A escolha deste tema foi porque é uma curiosidade dos alunos sobre saber que é família, a importância de ter a família por perto, conhecendo seus componentes, estrutura familiar e as vivências que seus pais ou avós tiveram nas suas brincadeiras infantis e quais músicas infantis eles cantam no tempo da sua infância, também por que a escola está envolvida em um projeto da prefeitura do município de Panambi, para que a turma de educação infantil apresente uma cantiga antiga.

2 Para montar o boneco cada aluno escolheu 29 tampas perfuradas pela estagiária. Iniciou-se a montagem do boneco pelas pernas. Para compor as pernas foram utilizados dois Para montar o boneco cada aluno escolheu 29 tampas perfuradas pela estagiária. Iniciou-se a montagem do boneco pelas pernas. Para compor as pernas foram utilizados dois
elásticos de $15 \mathrm{~cm}$. Montou-se um das pernas e com um arame passou-se pelos dois orifícios perfurados no copinho de iogurte inserindo mais 8 tampas no restante do elástico formando a segunda perna do boneco.Para compor os braços utilizou-se $50 \mathrm{~cm}$ de elástico. Primeiramente dividiu-se o elástico ao meio e fez-se um laço de aproximadamente 6 ponta do elástico nos orifícios direito e esquerdo do copinho de iogurte, em seguida colocou-se 6 tampinhas em cada ponta do elástico os quais formaram os braços do boneco. Na ponta do elástico nos braços e nas pernas finalizaram com um nó para que as tampas não escapassem.Na bolinha do rolon foram pintados os olhos, o nariz e a boca.
} 


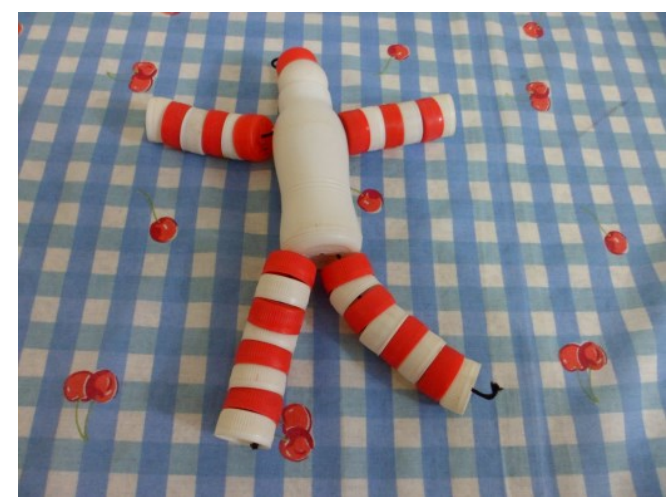

Figura 1 - Imagem do boneco

Fonte: Autora, 2012.

A partir de sugestão dada pela estagiária foi instituído nas sextas-feiras, o dia do brinquedo e durante as semanas que foi realizado o estágio, as crianças traziam brinquedos seus, mas o boneco também. E pelo relato da professora regente, até o final do ano as crianças ainda levavam o boneco para brincar na escola.

Para Kishimoto (2010), as práticas pedagógicas devem garantir experiências diversas, com destaque para o aprendizado do corpo humano, promovendo a interação, cuidado, preservação e sustentabilidade e não do desperdício dos recursos naturais. Ao solicitar os materiais de sucata, foi abordada a responsabilidade de reutilizar materiais para a fabricação de brinquedos, mas apenas aqueles que não são perigosos de serem reutilizados. Percebeu-se a animação das crianças, que participaram e se envolveram ativamente na atividade. Após, a professora regente registrou a atividade, tirou foto dos bonecos e as crianças relataram a experiência e o motivo desta atividade" (22/05/2012).

\section{Considerações Finais}

Ao realizar atividades envolvendo o boneco, foi possível explorar, cores, quantidades, diferentes tamanhos, as partes do corpo humano. Cada boneco possuía as suas características próprias, isso o diferenciava nas respostas, foi muito gratificante. Enfim, a cada semana de aula, aparecia um novo desafio e novas descobertas pelas crianças. Aprendi que é importante utilizar em sala de aula, atividades dinâmicas que permitam às crianças participarem e brincarem, incentivam aprendizagens e a construção do conhecimento.

As crianças aprendem interagindo umas com as outras, e o que fé construído pelas crianças foi tão significativo que continuou sendo referências nas brincadeiras facilitando a aprendizagem infantil. Os pais relatavam que as crianças comentavam sobre as atividades desenvolvidas em sala de aula.

Este artigo foi um relato parcial de vivências como professora estagiária, no qual tive a oportunidade de escrever sobre minha própria prática docente. Aprendi a importância de ouvir as crianças, registrar e refletir referenciada em autores que permitem compreender e contextualizar a prática pedagógica. Espero que este artigo venha a contribuir para que outros docentes também se inspirem e usem sua criatividade para inovar levando em consideração que as aprendizagens são mais significativas quando as crianças aprendem através de atividades lúdicas. Lembrem-se em reutilizar diferentes materiais cuidando e preservando o meio ambiente.

\section{Referências}

ANDRADE, David. Arte Viva. Disponível em:< http://www.artenaescola.org.br/sala relato.php?id relato=38>.Acesso em: 28 nov. 2011.

BASSO, C. M. Algumas Reflexões Sobre o Ensino Mediado Por Computadores. Disponível em: $<$ http://www.ufsm.br/lec/02 00/Cintia-L\&C4.htm>. Acesso em: 26 nov 2011. 
BRANDÃO,C. R.Pesquisa Participante.São Paulo, ed. Brasiliense, 2006.

Brasil. Ministério da Educação. Secretaria de Educação Básica. Diretrizes curriculares nacionais para a educação infantil / Secretaria de Educação Básica. - Brasília: MEC, SEB, 2010.

BRASIL. Ministério da Educação. Lei de Diretrizes e Bases da Educação Nacional - $\mathrm{n}^{\circ}$ 9.394/96 Brasília, 1996.

FREIRE, Paulo. A Educação na Cidade. São Paulo, SP: Cortez, 2002.

HEMPE, Cléa. Análise do Gerenciamento dos Resíduos Sólidos em Panambi RS: 1955-2012. $\begin{array}{llll}\text { Dissertação de } & \text { Mestrado, } & 2013 . & \text { Disponível }\end{array}$ em: <http://w3.ufsm.br/ppggeo/images/dissertacoes/Dissertao\%20Analise\%20dos\%20Res.Solidos\% 20.pdf>. Acesso em: set. 2014.

JÚNIOR, J.R .Z. Jogo e Ludicidade: Contribuições para o desenvolvimento infantil, 2009. Disponível em: < http://www.efdeportes.com/efd137/jogo-e-ludicidade-o-desenvolvimentoinfantil.htm >. Acesso em: 26 nov. 2011.

MAURICIO, Juliana. T. Aprender Brincando: O Lúdico na Aprendizagem. Disponível em: < www.profala.com/arteducesp140.htm>. Acesso em: 21 nov. 2011.

Material didático disponível na disciplina de Metodologia da Pesquisa: Uma Reflexão Sob o Ato de Brincar, disponível em: <http://www.profala.com/arteducesp94.htm>. Acessado em: 07 jul. 2011.

LAKATOS, E. e MARCONI, M. M . Metodologia do Trabalho Científico. São Paulo, Atlas, 1992.

NEGRINE, Airton. Aprendizagem e desenvolvimento infantil. Porto Alegre: PRODIL, 1994.

OLIVEIRA, E .E.,Nov.2006. Piaget, Vygotsky e Winnicott: relação com jogo infantil e sua aplicação na área da psicopedagogia. Disponível em: <http://www.abpp.com.br/artigos/61.htm.> Acesso em 28 nov. 2011.

OSTETTO, Luciana Esmeralda(org).Educação Infantil-Saberes e fazeres da formação de professores.Campinas-SP,PAPIRUS, 2008.

PASCHOAL, Jaqueline Delgado. (Re)pensando a prática do educador infantil. In SANTOS, Santa Marli Pires dos (Org). Brinquedoteca: a criança, o adulto e o lúdico. Petrópolis, RJ, Vozes, 2000.

PEREIRA. J. E. N. O papel do professor na Educação Infantil na autonomia moral: Uma revisão da literatura, 2006. Disponível em: <http://www.artigos.com/artigos/humanas/educacao/opapel-do-professor-na-educacao-infantil-8346/artigo/>. Acesso em: 26 nov. 2011.

PEREIRA, Marilda Valerio. O lúdico na educação infantil, 2009. Disponível em: $<$ http://blig.ig.com.br/maeducacao/2009/08/30/artigo-o-ludico-na-educacao-infantil/. > Acesso em: 21 nov. 2011.

PERRENOUD, Philippe. A prática reflexiva no ofício de professor: profissionalização e razão pedagógica. Porto Alegre: ARTMED, 2002.

SANTOS, Santa Marli Pires. Espaços lúdicos - brinquedoteca. In: SANTOS, Santa Marli Pires. Brinquedoteca- a criança, o adulto e o lúdico. Petrópolis, RJ: Vozes, 2000. 
KISHIMOTO, Tizuko Morchida (org.). Jogo, brinquedo e a educação. 11ed São Paulo, SP: Cortez, 1998. 1998.

Brinquedos e brincadeiras na educação infantil. Disponível em http://search.sweetim.com/search.asp? src $=2 \& \mathrm{crg}=3.1010006 \& \mathrm{q}=\mathrm{mec}+$ brinquedos $+\mathrm{e}+$ brincadeiras $+\mathrm{n}$ a+educa \%C3\%A7\%C3\%A3o+infantil+kishimoto Acesso em: 21 nov. 2011.

WAJSKOP Gisela. Brincar na pré-escola. $3^{a}$ edição. São Paulo: Cortez, 1995. Coleção Questões da nossa época, v. 48. 